ARTICLE INFO

Received

May 19, 2020

Revised

July 10,2020

Accepted

July 13, 2020

Published

August 15, 2020

*Corresponding author

Shahzad Hussain

E-mail

shhussain@ksu.edu.sa

Phone

+96-6590623370

Keywords

Rice starch

Corn starch

Wheat starch

Chickpea starch

Starch cell

Rheometer

How to cite

Hussain S. Pasting and

rheological properties of

different starches using starch

cell of discovery hybrid

rheometer. Sci Lett 2020;

8(3):93-99
Open Access

\section{Pasting and Rheological Properties of Different Starches Using Starch Cell of Discovery Hybrid Rheometer}

\author{
Shahzad Hussain* \\ Department of Food Science and Nutrition, King Saud University, PO Box 2460, 11451 - \\ Riyadh, Saudi Arabia
}

\section{Abstract}

The study was conducted to evaluate the pasting and rheological measurements of four different starches (wheat, rice, corn and chickpea) using starch pasting cell of the hybrid rheometer. The experiment was planned to initially record the pasting behavior of starches in the starch cell using heating, holding and cooling program. The cooked gels were then subjected to steady shear and dynamic rheological measurements in the same cell. The highest peak and the final and setback viscosities were recorded for chickpea starch while the lowest values were obtained for the rice starch. The pasting curves of different starches represented the typical curve as observed using the traditional visco-analyzer or viscoamylograph. All the studied starches represented shear-thinning nonNewtonian behavior ( $n$ was less than 1 ) when studied for their steady shear properties. The starches could be classified from less to more pseudoplastic as rice>corn >wheat>chickpea. The activation energy of rice starch was highest $(142719 \mathrm{~J} / \mathrm{mol})$ while the activation energy of chickpea starch was lowest among all the starches $(13291 \mathrm{~J} / \mathrm{mol})$. The storage moduli, loss moduli and dynamic mechanical loss tangent were increased with increasing the frequency, and the crossover was also observed in corn, rice and wheat starch at the higher frequency. It is well evident from all the studied parameters that starch cell can be conveniently used to study the pasting and rheological properties of starches. 


\section{Introduction}

Starches represent the second most abundant biopolymer on earth next to cellulose and are stored as major energy reserves in different parts of plants [1]. Starches are extracted and widely used in food, feed, pharmaceutical and other industries as an ingredient or processing aid [2]. The starches are produced from different sources, including cereals like corn, rice, wheat, sorghum, barley, oat (40$90 \%)$, tubers like potato, sweet potato $(65-85 \%)$, roots like tapioca, arrowroot (30-70\%), legumes like chickpea, kidney beans, peanuts (25-50\%) and some immature fruits like banana and mangoes (up to $70 \%$ ) [3]. The starches are used in their native or modified form in different food products as thickening, stabilizing, foaming, texturizing, and bulking agents $[4,5]$. Properties of starches may vary depending on their origin, processing method, form, amylose and amylopectin ratio, chain length, granule size and shape. Starches are sometimes mixed with different additives, modified physically or enzymatically to achieve desired objectives $[4,6$, 7]. The starches are usually studied for their pasting, thermal, textural and freeze-thaw stability properties. The nature, functionality and other properties of starches are extensively studied by several researchers by different analytical techniques $[8,9]$.

Pasting behavior like pasting temperature, peak time, peak viscosity, final viscosity, breakdown viscosity and setback viscosities of starches are traditionally studied by amylograph or rapid viscoanalyzer [10, 11]. The thermal characterization of starches for their heat capacity is onset temperature, gelatinization temperature or glass transition, if any, using differential scanning calorimeter [12-14]. The freeze-thaw stability and retrogradation behaviors of starches are usually studied by syneresis and texture profile analysis. Cooked starch gels are also characterized for their rheological behavior like steady shear measurements (pseudo-plasticity, shear-thinning, etc.), dynamic properties (elastic or viscous properties) and temperature dependency $[15,16]$. The traditional methods to determine pasting, rheological and textural characterization are usually performed individually and are often timeconsuming, laborious and need separate analytical equipment. The present study was planned to study the pasting properties and all types of rheological measurements of four different starches using the same sample in the starch pasting cell of hybrid rheometer.

\section{Materials and Methods}

\section{Collection of raw materials}

Wheat and chickpea grains were procured from the local market of Riyadh, Saudi Arabia and starch from grains was isolated according to the methods reported in our previous research [17]. Rice starch was provided by Winlab Laboratory Chemicals, Leicestershire, UK, while corn starch was purchased from ARASCO, Saudi Arabia. Starches were isolated from wheat and chickpea grains, according to the respective methods as mentioned in a previous report [13]. The starches were stored in airtight jars until further use.

\section{Pasting properties of starches}

Starch pasting cell of Discovery Hybrid Rheometer (TA Instruments, New Castle, USA) was used to determine the pasting properties of starch as well as the rheological and temperature-dependent characteristics of starch gels using the same sample. The sample was placed in the starch cell $(3 \mathrm{~g}$ on $14 \%$ moisture basis) and distilled water was added to achieve the final slurry weight of 28 grams. The operational gap between the base of the starch cell and the rotating paddle was adjusted to $5500 \mu \mathrm{m}$ in all types of measurements. Pasting properties of starches were recorded by holding the sample at $50^{\circ} \mathrm{C}$ for 2 minutes and then the temperature was ramped to $95^{\circ} \mathrm{C} @ 10^{\circ} \mathrm{C} / \mathrm{min}$, held at $95^{\circ} \mathrm{C}$ for 4 minutes and then finally ramped down to $50^{\circ} \mathrm{C} @$ $10^{\circ} \mathrm{C} / \mathrm{min}$ and kept at $50^{\circ} \mathrm{C}$ for 2 minutes. The speed of paddle was maintained at $132 \mathrm{rad} / \mathrm{s}$ during the whole pasting experiment. The data were then plotted using sigma plot and tabulated as peak viscosity $(\mathrm{cP})$, final viscosity $(\mathrm{cP})$, setback viscosity (cP), peak time (min) and pasting temperature $\left({ }^{\circ} \mathrm{C}\right)$.

\section{Rheological properties and activation energy of starches}

Steady shear behavior (shear rate vs shear stress) and temperature dependency $\left(50^{\circ} \mathrm{C}, 60^{\circ} \mathrm{C}\right.$ and $70^{\circ} \mathrm{C}$ ) of cooked starch gels were recorded at a variable shear rate of 1 to 200/s (200 s). The data were fitted to the power-law model (1), while temperature dependency was estimated by using the Arrhenius equation (2).

$\mathrm{T}=K_{\gamma}{ }^{n}$ 
Where $\mathrm{T}=$ shear stress $(\mathrm{Pa} \cdot \mathrm{s}), K=$ consistency coefficient $(\mathrm{Pa} \cdot \mathrm{s}), \gamma=$ shear rate $\left(\mathrm{s}^{-1}\right)$ and $n=$ flow behavior index (dimensionless).

$\left(\ln \mu a=\ln \mu^{o}+E a / \mathrm{RT}\right)$

Where $\mu a=$ apparent viscosity, $\mu_{o}=$ frequency factor, $\mathrm{R}=$ gas constant, $E a=$ energy of activation and $\mathrm{T}=$ absolute temperature $(\mathrm{K})$.

The frequency factor is a constant that relates to the frequency of the colliding molecules with enough energy to start a reaction, and it varies from reaction to reaction. The reciprocals of temperatures $\left(50^{\circ} \mathrm{C}\right.$, $60^{\circ} \mathrm{C}$ and $70^{\circ} \mathrm{C}$ converted to Kelvin as 323.15 , 333.15 and 343.15 , respectively, were plotted against the natural $\log$ of $K$ values. After applying the linear regression, the slope was multiplied with universal gas constant $(\mathrm{R}=8.314 \mathrm{~J} / \mathrm{mol} \cdot \mathrm{K})$ to get the value of $\mathrm{Ea}$, while the inverse log of intercept was considered as $\mu_{o}=$ frequency factor. Dynamic rheological properties of cooked gels were also determined using the same cooked gel and starch cell. The 5\% constant strain was used after determining the linear viscoelastic region. The storage moduli $\left(G^{\prime}\right)$, loss moduli $\left(G^{\prime \prime}\right)$ and dynamic mechanical loss tangent $\left(\tan \delta=G^{\prime \prime} / G^{\prime}\right)$ were recorded at $70^{\circ} \mathrm{C}$ within frequency sweeps ranging from $0.1-100 \mathrm{rad} / \mathrm{s}$.

\section{Results and Discussion}

Pasting properties of different starches are the changes in their viscosity as a function of time and temperature when they are cooked in excess water using a controlled program. The conventional equipment which is used to determine the pasting properties are visco-amylograph and rapid viscoanalyzer. The starch cell of a hybrid rheometer can also be used but it is not much studied. All the machines are based on control programs that monitor the changes in viscosity. The programs describe the pasting behavior in three steps: (1) heating period, in which the temperature of starch suspension is raised stepwise from room to $95^{\circ} \mathrm{C}$; (2) suspension is maintained at a maximum temperature to observe hot paste viscosity and breakdown while stirring; and (3) stepwise cooling of suspension to approximately $50^{\circ} \mathrm{C}$ to determine the short term retrogradation (setback) [18]. Pasting properties of different starches are tabulated in Table 1 and their corresponding profiles are presented in Fig. 1. The highest peak, final and setback viscosities were recorded for chickpea

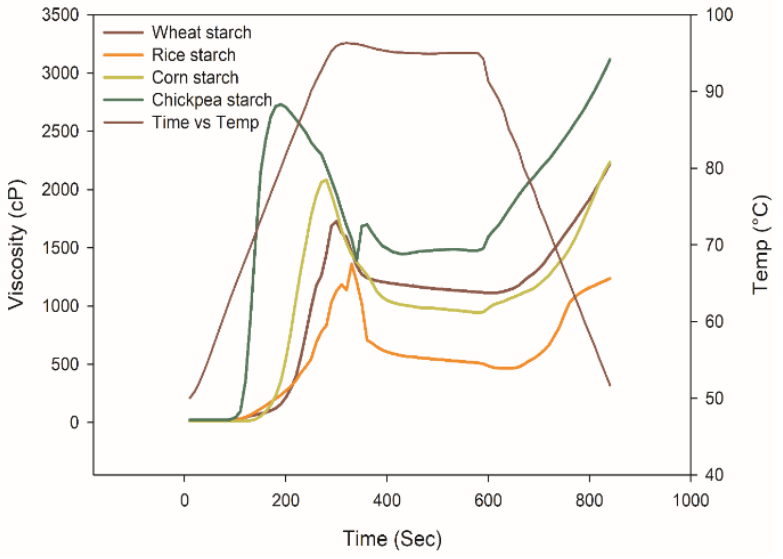

Fig. 1 Pasting profiles of wheat, rice, corn and chickpea starches using starch cell.

starch while lowest for the rice starch. It can be observed from the data that peak time (time at the peak viscosity) was higher for rice starch $(5.5 \mathrm{~s})$ while the lowest was observed for chickpea starch (3.16 s). Pasting temperature of starches varied between $60^{\circ} \mathrm{C}$ to $68^{\circ} \mathrm{C}$. The pasting curves of different starches shown in Fig. 1 represents the typical curve as observed using a traditional viscoanalyzer or visco-amylograph. The values of different pasting parameters determined using a hybrid rheometer are well comparable to those recorded using traditional amylograph or rapid visco-analyzer (Table 1). The difference in peak viscosities of different starch suspensions depends on concentration, granule size, granule rigidity, amylose content, amylose leaching, lipid contents and swelling power [19]. The presence of amylose lipid complex in cereal starches hinders the swelling power of starch, lower peak and setback viscosities. The higher setback and peak viscosities of chickpea starch could be attributed to the presence of higher amylose $(29.5 \%)$ content as compared to cereal starches (wheat, 23.4\%; rice, $20.5 \%$ and corn, $22.1 \%$ ). The results of our studies are supported by the previous work reported by several researchers $[1,20,21]$.

\section{Steady shear properties of starch gels}

Starch pastes when studied under the variable stress behave as non-Newtonian (shear-thinning or thixotropic), i.e., the shear stress did not increase linearly with increasing shear rate. The shear stress vs shear rate data is widely studied by fitting them in most commonly used mathematical models like powerlaw and Herschel-Bulkley models. In the present study, data were fitted to power-law model 
Table 1 Pasting properties of wheat, rice, corn and chickpea starches determined by using starch-cell of the hybrid rheometer.

\begin{tabular}{|c|c|c|c|c|c|}
\hline & $\begin{array}{c}\text { Peak viscosity } \\
\text { (cP) }\end{array}$ & $\begin{array}{c}\text { Final viscosity } \\
\text { (cP) }\end{array}$ & $\begin{array}{c}\text { Setback } \\
\text { viscosity }(\mathbf{c P}) \\
\end{array}$ & $\begin{array}{c}\text { Peak time } \\
(\mathrm{min})\end{array}$ & $\begin{array}{c}\text { Pasting temp. } \\
\left({ }^{\circ} \mathrm{C}\right)\end{array}$ \\
\hline Wheat starch & $1727 \pm 31$ & $2222 \pm 11$ & $1108 \pm 20$ & $5.00 \pm 0.06$ & $61.13 \pm 0.36$ \\
\hline Rice starch & $1361 \pm 55$ & $1236 \pm 18$ & $771 \pm 31$ & $5.50 \pm 0.11$ & $60.50 \pm 0.47$ \\
\hline Corn starch & $2084 \pm 57$ & $2236 \pm 17$ & $1293 \pm 43$ & $4.67 \pm 0.10$ & $68.12 \pm 0.82$ \\
\hline Chickpea starch & $2731 \pm 47$ & $3117 \pm 15$ & $1671 \pm 25$ & $3.16 \pm 0.05$ & $62.50 \pm 0.45$ \\
\hline
\end{tabular}

Table 2 Flow behavior index $(n)$ and consistency coefficient/viscosity $(K)$ of wheat, rice, corn and chickpea starches at different temperatures obtained through the power-law model.

\begin{tabular}{|c|c|c|c|c|c|c|c|c|c|}
\hline Parameters & \multicolumn{3}{|c|}{$\boldsymbol{K}\left(\mathrm{Pa} \mathrm{s}^{\mathrm{n}}\right)$} & \multicolumn{3}{|c|}{$n$} & \multicolumn{3}{|c|}{$R^{2}$} \\
\hline Temp $\left({ }^{\circ} \mathbf{C}\right)$ & 50 & 60 & 70 & 50 & 60 & 70 & 50 & 60 & 70 \\
\hline Wheat starch & 7.41 & 5.11 & 1.84 & 0.40 & 0.55 & 0.72 & 0.98 & 0.98 & 0.97 \\
\hline Rice starch & 4.78 & 0.57 & 0.22 & 0.52 & 0.90 & 0.93 & 0.98 & 0.98 & 0.97 \\
\hline Corn starch & 8.61 & 3.16 & 1.19 & 0.41 & 0.64 & 0.80 & 0.99 & 0.95 & 0.97 \\
\hline Chickpea starch & 10.49 & 8.63 & 7.87 & 0.37 & 0.55 & 0.57 & 0.97 & 0.97 & 0.97 \\
\hline
\end{tabular}

Table 3 Activation energy parameters of wheat, rice, corn and chickpea starches.

\begin{tabular}{|c|c|c|c|}
\hline Parameters & $\mu \circ\left(\operatorname{Pa~}^{n}\right)^{a}$ & $\mathrm{E}_{\mathrm{a}}(\mathrm{J} / \mathrm{mol})^{\mathrm{b}}$ & $R^{2}$ \\
\hline Wheat starch & $1.84 \times 10^{-34}$ & 97981 & 0.99 \\
\hline Rice starch & $2.41 \times 10^{-52}$ & 142719 & 0.96 \\
\hline Corn starch & $4.61 \times 10^{-40}$ & 112526 & 0.99 \\
\hline Chickpea starch & $2.44 \times 10^{-03}$ & 13291 & 0.96 \\
\hline
\end{tabular}

at three different temperatures. It can be professed from the Table 2 that the shear rate $(1 / \mathrm{s})$ versus shear stress $(\sigma)$ data of all samples fitted well to the simple power-law model $\left(R^{2}=0.95-0.99\right)$. The power-law model describes the two most important properties of starch; $n$ (flow behavior index) and $\mathrm{K}$ (consistency coefficient/viscosity). It is evident from Fig. 2 and the data presented in Table 2 that all the studied starches represented shear-thinning non- Newtonian behavior ( $n$ is less than 1 ). If the value of $n$ deviates from 1 is considered as more pseudoplastic of more shear thinning. The rice starch showed less shear-thinning (less pseudoplastic) while chickpea starch showed the highest shear thinning at all the three studied temperatures. The starches can be classified from less to more pseudoplastic as follows: rice>corn $>$ wheat $>$ chickpea. It can also be observed from the Table 2 that all the starches at $70^{\circ} \mathrm{C}$ were less pseudoplastic than at $50^{\circ} \mathrm{C}$ (more pseudoplastic).

The second information obtained from the power-law model is $K$ value (consistency coefficient) which directly relates to the viscosity of the starch paste. The value of $K$ was highest in chickpea starch $\left(10.49 \mathrm{~Pa} \mathrm{~s}^{\mathrm{n}}\right)$ and lowest in rice starch $\left(4.78 \mathrm{~Pa} \mathrm{~s}^{\mathrm{n}}\right)$ and it relates to the results obtained from the pasting profile of starches (Table 1). As expected, the value of $\mathrm{K}$ was lower at a higher temperature $\left(70^{\circ} \mathrm{C}\right)$ as compared to a lower temperature $\left(50^{\circ} \mathrm{C}\right)$. There was a linear decrease in the $K$ value of all the starches when they were studied at higher temperatures (Fig. 2). The values of $K$ obtained at three different temperatures were further fitted to the Arrhenius equation and activation energy was calculated. Activation energy is defined as the amount of the minimum energy required to start a reaction. It is always necessary to evaluate the effect of temperature on starch because heating at different temperatures could affect the properties of starch-containing foods. The higher value of $R^{2}$ (0.96-0.99) presented in Table 3 indicates a good relationship between apparent viscosity and temperatures of starch gels and it obeys the Arrhenius model. The activation energy of rice starch was highest $(142719 \mathrm{~J} / \mathrm{mol})$ while the activation energy of chickpea starch was lowest among all the starches $(13291 \mathrm{~J} / \mathrm{mol})$. The higher activation energy of a biomaterial is reflective of its higher dependence on temperature [22]. The increase in the value of $n$ (flow behavior index), reduction in viscosity at higher temperatures signifies the temperature dependence of biomaterials. It can be easily interpreted from the above results that chickpea starch is more pseudoplastic (more shear thinning), more viscous and less temperature-dependent (requires less activation energy) while rice starch is less pseudoplastic (less shear thinning), less viscous and more temperature-dependent (requires more 

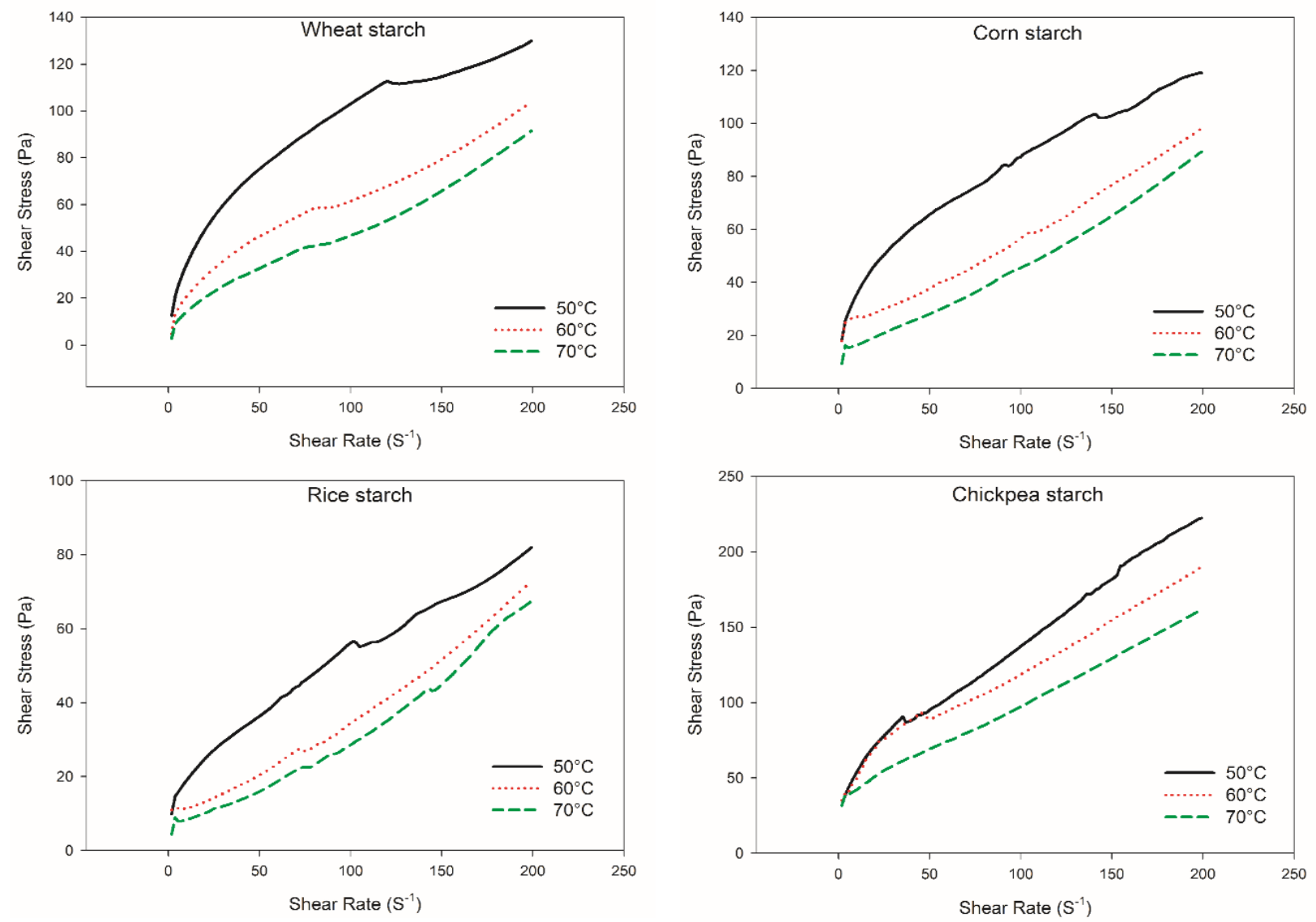

Fig. 2 Shear rate $\left(\mathrm{S}^{-1}\right)$ vs shear stress $(\mathrm{Pa})$ plots of wheat, rice, corn and chickpea starches at $50^{\circ} \mathrm{C}, 60^{\circ} \mathrm{C}$ and $70^{\circ} \mathrm{C}$.

activation energy) among all the studied starches. Several researchers have reported the significant influence of temperature on the viscosity of different bio-materials [23-25].

\section{Dynamic rheological properties of starch gels}

Dynamic rheological properties of starch gels are studied by dynamic rheometer, where gels are placed between the plates and cones, which allows continuous assessment of starch pastes under various stresses, temperatures or frequencies. In this study, dynamic rheological measurements were carried out using starch cell instead of traditional cone and plate geometry. The data were collected for storage or elastic modulus $\left(\mathrm{G}^{\prime}\right)$, loss or viscous modulus $\left(\mathrm{G}^{\prime \prime}\right)$ and loss tangent $\left(\tan \delta=\mathrm{G}^{\prime \prime} / \mathrm{G}^{\prime}\right)$. The $\mathrm{G}^{\prime}$ is the measure of elastic properties of starch gels (solid-like behavior) and measured as deformation energy measured per cycle of deformation. The $\mathrm{G}^{\prime \prime}$ indicates the viscous properties (liquid-like behavior) of starch gels measured as energy dissolute as heat during per cycle of deformation. The value of $\tan \delta$ also helps to define the nature of starch gels; if the $\tan \delta>1$, the material is considered as liquid-like while $\tan \delta<1$ represents solid-like behavior [26]. It is evident from the data presented in Fig. 3 that storage moduli, loss moduli and $\tan \delta$ were increased with increasing the frequency and crossover was also observed in corn, rice and wheat starch at a higher frequency. Chickpea starch did not show any crossover throughout the studied frequency range. It can also be observed in Fig. 3 that storage moduli of corn, rice and chickpea starches were much higher than their loss moduli; representing the dominance of elastic properties over viscous properties at the low frequencies and the behavior was changed at higher frequencies where crossover happened and viscous properties dominated the elastic ones. The value of storage and loss moduli was not much separated from each other in case of wheat starch and cross over took place way before the other three starches. The values of $\tan \delta$ at $10 \mathrm{rad} / \mathrm{s}$ were $0.99,0.63,0.34$ and 0.15 for wheat, rice, corn and chickpea starch, respectively. The value of $\tan \delta$ at this frequency value suggested that wheat starch was more liquid like (value being 

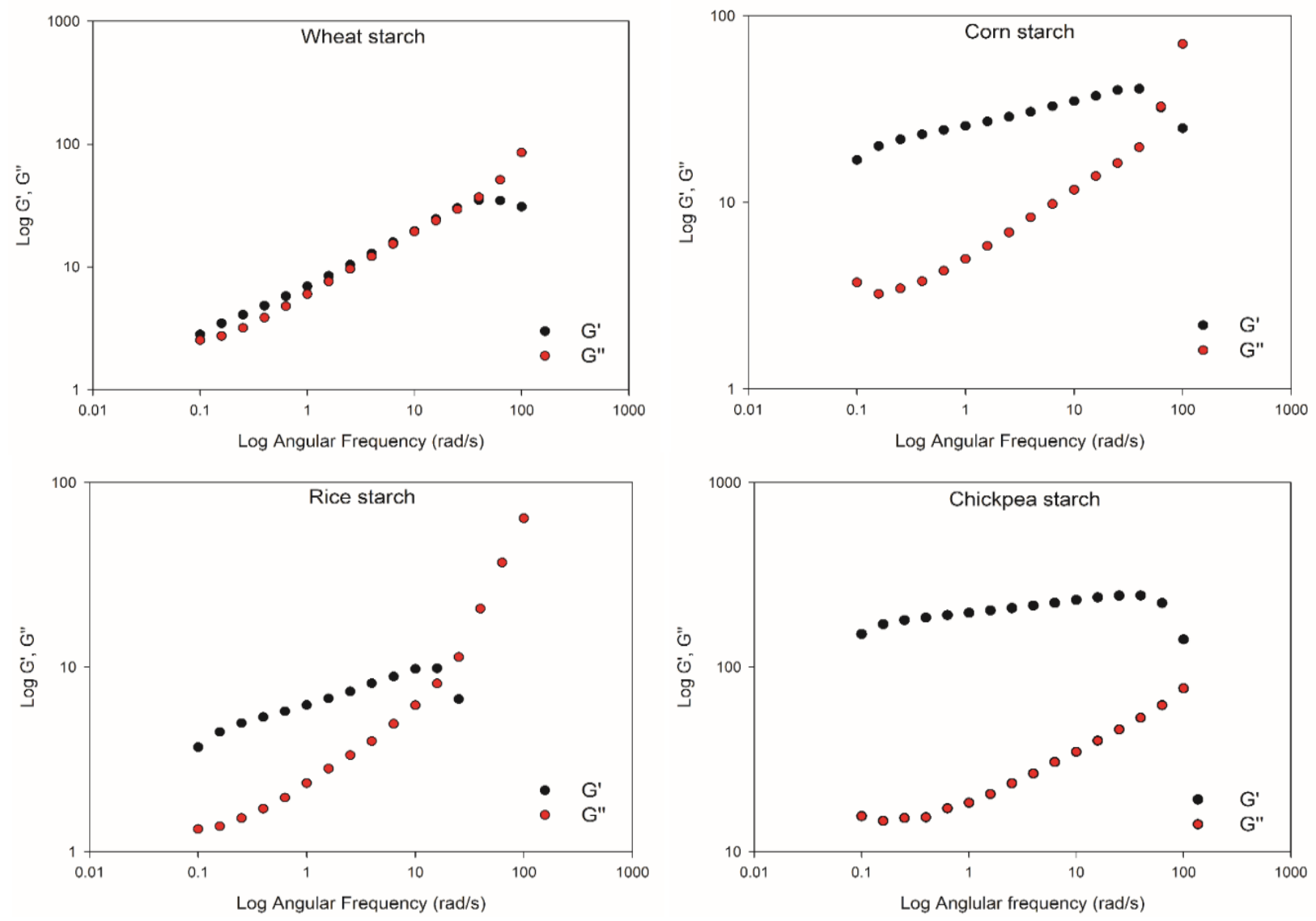

Fig. 3 Storage moduli $\left(G^{\prime}\right)$ and loss moduli $\left(G^{\prime \prime}\right)$ vs angular frequency plots of wheat, rice, corn and chickpea starches at $70^{\circ} \mathrm{C}$.

close to 1) and chickpea starch was more solid like (value being away from 1) (Fig. 4). Several factors are considered to be responsible for differences in the rheological properties of different starches. Higher amylose content is linked to higher $\mathrm{G}^{\prime}$ and $\mathrm{G}^{\prime \prime}$ of different starches [27]. The presence of higher amylose value of chickpea starch resulted in higher values of $G^{\prime}$ and $G^{\prime \prime}$. The granular structure of the starch is also responsible for the differences in rheological behaviors. The presence of large and cuboidal and irregular granules in potato starch resulted in higher values of $G^{\prime}$ and $G^{\prime \prime}$ when compared to small and oval granules [28].

\section{Conclusion}

The dynamic rheometer was used to evaluate the pasting, steady and dynamic properties of four different starches. Data for all the studied parameters were collected from the same sample rather than using separate samples every time and all the measurements were programmed and collected in a single go. It can be concluded that the results are repeatable and in close conformity with the previously reported methods being used for starch characterization. The pasting profiles of starches were similar to those earlier reported using traditional rapid viscoanalyzer or viscoamylograp

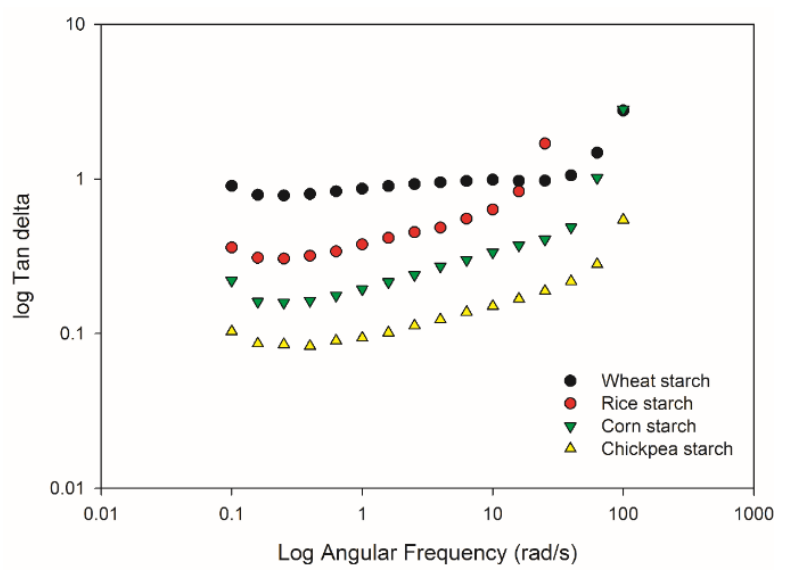

Fig. 4 Tan delta vs angular frequency plots of wheat, rice, corn and chickpea starches at $70^{\circ} \mathrm{C}$. 
Chickpea starch represented the highest values of peak and setback viscosities, whereas rice starch showed the least values. Though all the starches were pseudoplastic in nature, rice starch was least of all and required higher activation energy. The dynamic moduli of the starches determined using starch cell demonstrated the dominance of elastic properties over viscous properties at low frequency and elasticity decreased at higher frequencies.

\section{Conflict of Interest}

The author declares no conflict of interest in this study.

\section{References}

[1] Waterschoot J, Gomand SV, Fierens E, Delcour JA. Production, structure, physicochemical and functional properties of maize, cassava, wheat, potato and rice starches. Starch-Stärke 2015; 67(1-2):14-29.

[2] Santana ÁL, Meireles MAA. New starches are the trend for industry applications: a review. Food Pub Health. 2014; 4(5):229-41.

[3] Singh J, Kaur L, McCarthy O. Factors influencing the physico-chemical, morphological, thermal and rheological properties of some chemically modified starches for food applications-A review. Food Hydrocoll 2007; 21(1):1-22.

[4] Shen Y, Zhang N, Xu Y, Huang J, Wu D, Shu X. Physicochemical properties of hydroxypropylated and cross-linked rice starches differential in amylose content. Int J Biol Macromol 2019; 128:775-81.

[5] Saleh A, Mohamed A, Alamri M, Hussain S, Qasem A, Ibraheem M, et al. Nonfat set yogurt: effect of okra gum and various starches on the rheological, sensory, and storage qualities and wheying-off. J Chem 2020; 5091970.

[6] Wen Y, Yao T, Xu Y, Corke H, Sui Z. Pasting, thermal and rheological properties of octenylsuccinylate modified starches from diverse small granule starches differing in amylose content. J Cereal Sci 2020; 103030.

[7] Shahzad SA, Hussain S, Mohamed AA, Alamri MS, Ibraheem MA, Qasem AAA. Effect of hydrocolloid gums on the pasting, thermal, rheological and textural properties of chickpea starch. Foods 2019; 8(12):687.

[8] Abd Karim A, Norziah M, Seow C. Methods for the study of starch retrogradation. Food Chem 2000; 71(1):9-36.

[9] Zhang Y, Li G, Wu Y, Yang Z, Ouyang J. Influence of amylose on the pasting and gel texture properties of chestnut starch during thermal processing. Food Chem 2019; 294:378-83.

[10] Suh DS, Jane Jl. Comparison of starch pasting properties at various cooking conditions using the micro viscoamylo-graph and the rapid visco analyser. Cereal Chem 2003; 80(6):745-9.

[11] Hussain S. Native rice starch and linseed gum blends: Effect on the pasting, thermal and rheological properties.
Czech J Food Sci 2015; 33(6):556-63.

[12] Normand F, Marshall W. Differential scanning calorimetry of whole grain milled rice and milled rice flour. Cereal Chem 1989; 66(4):317-20.

[13] Hussain S, Alamri MS, Mohamed AA. Rheological, thermal and textural properties of starch blends prepared from wheat and Turkish bean starches. Food Sci Technol Res 2013; 19(6):1141-7.

[14] Varavinit S, Shobsngob S, Varanyanond W, Chinachoti $P$, Naivikul O. Effect of amylose content on gelatinization, retrogradation and pasting properties of flours from different cultivars of Thai rice. Starch-Stärke 2003; 55(9):410-415.

[15] Hsu S, Lu S, Huang C. Viscoelastic changes of rice starch suspensions during gelatinization. J Food Sci 2000; 65(2):215-20.

[16] Zheng Y, Sun W, Yang W, Chen S, Liu D, Tian J, et al. The influence of xanthan gum on rheological properties and in vitro digestibility of Kudzu (Pueraria lobata) Starch. Starch-Stärke 2020; 72(3-4):1900139.

[17] Hussain S, Alamri MS, Mohamed AA, Ibraheem MA, Qasem A, Abdo A. Modification of starch pasting, textural and rheological attributes by blending wheat and chickpea starches. Pak J Agric Sci 2018; 55(4):905-912.

[18] Saunders J, Izydorczyk M, Levin DB. Limitations and challenges for wheat-based bioethanol production. In: Economic on Effects Biofuel Prod 2011; pp. 429-452.

[19] Srichuwong S, Sunarti TC, Mishima T, Isono N, Hisamatsu M. Starches from different botanical sources II: Contribution of starch structure to swelling and pasting properties. Carbohyd Polym 2005; 62(1):25-34.

[20] Zhu F, Corke H. Gelatinization, pasting, and gelling properties of sweetpotato and wheat starch blends. Cereal Chem 2011; 88(3):302-9.

[21] Alcázar-Alay SC, Meireles MAA. Physicochemical properties, modifications and applications of starches from different botanical sources. Food Sci Technol 2015; 35(2):215-36.

[22] Barbosa CV. Flow parameters of selected commercial semi-liquid food products. J Tex Stud 1983; 14:213-34.

[23] Sharoba A, Senge B, El-Mansy H, Bahlol HE, Blochwitz R. Chemical, sensory and rheological properties of some commercial German and Egyptian tomato ketchups. Europ Food Res Technol 2005; 220(2):142-51.

[24] Ibarz A, Garvin A, Costa J. Rheological behaviour of sloe (Prunus spinosa) fruit juices. J Food Engg 1996; 27(4):423-30.

[25] Ojewumi ME, Oyeyemi KG, Emetere ME, Okeniyi JO. Data on the rheological behavior of cassava starch paste using different models. Data In Br 2018; 19:2163-77.

[26] Waterschoot J, Gomand SV, Fierens E, Delcour JA. Starch blends and their physicochemical properties. Starch-Stärke 2015; 67(1-2):1-13.

[27] Tsai ML, Li CF, Lii CY. Effects of granular structures on the pasting behaviors of starches. Cereal Chem 1997; 74(6):750-757.

[28] Singh J, Singh N. Studies on the morphological, thermal and rheological properties of starch separated from some Indian potato cultivars. Food Chem 2001;75(1):67-77. 